\title{
TRANSANAL ENDOSCOPIC MICROSURGERY (TEM): A MINIMALLY INVASIVE PROCEDURE FOR TREATMENT OF SELECTED RECTAL NEOPLASMS
}

\author{
Microcirurgia endoscópica transanal (TEM): um procedimento minimamente invasivo para o \\ tratamento de neoplasias selecionadas do reto
}

Sergio C. NAHAS ${ }^{1,2}$, Caio S. R. NAHAS ${ }^{1,2}$, Carlos Frederico S. MARQUES ${ }^{1,2}$, Andre Roncon DIAS ${ }^{1}$, Wilson M. POLLARA ${ }^{1,2}$, Ivan CECCONELLO ${ }^{1,2}$

\begin{abstract}
From the ${ }^{1}$ Department of Gastroenterology, Surgical Division, School of Medicine, University of São Paulo, São Paulo, SP, Brazil (Departamento de Gastroenterologia, Divisão Cirúrgica, Faculdade de Medicina, Universidade de São Paulo, São Paulo, Brasil) and ${ }^{2}$ Octávio Frias de Oliveira São Paulo Cancer Institute, School of Medicine, University of São Paulo, São Paulo, SP, Brazil (Instituto do Câncer do Estado de São Paulo Octávio Frias de Oliveira - Faculdade de Medicina, Universidade de São Paulo, São Paulo, Brasil)
\end{abstract}

HEADINGS - Colorectal surgery. Combined modality therapy. Carcinoid.

\section{Correspondência: \\ Caio Sergio Rizkallah Nahas, \\ e-mail: caionahas@uol.com.br \\ Fonte de financiamento: não há \\ Conflito de interesses: não há \\ Recebido para publicação: 17/10/2009 \\ Aceito para publicação: 27/02/2010}

DESCRITORES - Cirurgia colorretal. Terapia combinada. Tumor carcinóide
ABSTRACT - Transanal endoscopic microsurgery (TEM) provides a minimally invasive alternative to radical surgery for excision of benign and malignant rectal tumors. TEM aims to provide an alternative to conventional abdominal surgery (low anterior resection or abdominoperineal amputations), which carries not inconsiderable morbidity and mortality. Based on review of the literature and in the authors experience, this review present the method and indications for TEM.

\section{INTRODUCTION}

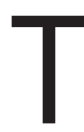
ransanal endoscopic microsurgery (TEM) was introduced in 1984 as a minimal invasive technique allowing the resection of adenomas and early rectal carcinomas unfit for local or colonoscopic excision requiring, therefore, major abdominal or abdominoperineal procedures. This is obtained with an endoscopic view of the rectum with reduced morbidity and mortality rates, decreased long-term functional dysfunction, decreased need for temporary or definitive colostomies, absence of scar, quick hospital discharge and fast recovery ${ }^{22,31}$. The cost savings associated with TEM seems significant due to short usage of operating room, brief use of analgesics, short of stay, quick return to regular activities and low rate of complications ${ }^{27,34}$.

TEM was initially proposed for adenomas and early rectal carcinomas 5 and its role in rectal cancer is still subject of much debate. This article presents a comprehensive review about the technique focusing in the indications 
and controversies of its use in the treatment of rectal neoplasms.

\section{METHODS}

Literature search was conducted with restriction to english language and only published material was considered. Search was performed at Medline, Cochrane library and Science Citation Index. Search terms were: transanal endoscopic microsurgery, TEM, rectal cancer, early rectal cancer and combined modality therapy.

\section{Technique}

TEM is a relatively new technique developed to allow excision of lesions located in the rectum. The patient undergoes a full bowel preparation and general anesthesia. Prophylactic antibiotics are performed routinely. Appropriate positioning of the patient in the operating table is crucial: supine, prone, or even lateral position may be required in order to keep the lesion positioned at six o'clock in the operating field. After a dilating digital exam a specially developed and well lubricated proctoscope (diameter: 40 millimeters, length: 20 centimeters) is inserted through the anus and fixed to the operating table. The rectum is maintained dilated with carbon dioxide insufflation. The faceplate of the proctoscope has three airtight ports for insertion of instruments, including dissecting forceps, needle holder and suction cannula. A forth port is exclusive for the insertion of a 40 degree optic which is connected to a video camera that transmits the image to a conventional monitor. The procedure is technically challenging because of the narrow operating field. Distal rectal lesions are more challenging to resect due to difficulties in maintaining the gas seal and in the instrumentation.

Lesions can be excised with partial or full-thickness of rectal wall. The injection of saline solution in the submucosa in a mucosectomy fashion may be used to facilitate the removal of benign lesions. Wound closure can be achieved, when desired, with clips or suture stitches. The surgical specimen is pinned out and oriented for pathological analysis of the margins.

\section{Indications}

The main indication for TEM is sessile rectal adenomas that are out of reach for transanal excision or that are unfit for colonoscopic removal ${ }^{11}$. TEM can access lesions that are up to 16 centimeters from the anal verge. The rectal lesion is usually resected in one piece, not necessarily having full thickness of the rectum wall, unless a malignant lesion is suspected. Diagnostic excision of polyps and other lesions of unclear pathology can also be achieved with this technique ${ }^{14}$.

\section{Benign lesions}

A shortage of randomized controlled trials exists and data can mainly be found as case series, frequently with short follow-up. A systematic review from Middleton, et al. ${ }^{27}$ included three comparative studies (including one randomized controlled trial) and 55 case series. They observed that TEM in adenoma has a recurrence rate of $5 \%$, a conversion rate of $5.7 \%$ (to abdominal resection or transanal excision) and a complication rate ranging from $3-7 \%$. TEM had a lower recurrence rate and lower cost in the treatment of adenomas when compared to anterior resection or local excision. Some of the studies reviewed in this article as well as some other case series will be further acknowledged.

Guerrieri, et al. ${ }^{16}$ reported the experience of six Italian centers with 588 adenomas resected by TEM with a median follow-up of 44 months. They observed a very low incidence of intraoperative complications (0.5\%), minor complications in $8.2 \%$ and major complications in $1.2 \%$ of the cases. Recurrence rate was $4.3 \%$ (23 patients) been managed by re-TEM ( $87 \%$ of the cases) or conventional surgery. There was no mortality.

Ganai, et al. ${ }^{14}$ removed 109 rectal adenomas with a recurrence rate of $15 \%$. They observed that lesions previously resected by polypectomies or transanal excision had an increased chance of recurrence $(32 \%$ versus $10 \%$ for lesions first resected with TEM). They also reported an increased chance for recurrence in adenomas with high-grade dysplasia ( $25 \%$ versus $11 \%$ ) therefore recommending a closer follow-up for these lesions.

McCloud, et al. ${ }^{26}$ resected 75 adenomas and reported complete excision as the main influence factor for recurrence. Although macroscopic excision is performed, histologic examination of the specimen may reveal an inadequate margin in a considerable number of cases. Lesions with compromised margins had a recurrence rate of $21.4 \%$ and $30.8 \%$ in six and 12 months, respectively, while completely resected adenomas had a significant lower recurrence rate $(0 \%$ and $2.6 \%$, in six and 12 months, respectively). In a median follow-up of 31 months recurrence observed was of $35.7 \%$ and $4.3 \%$ for incomplete and complete excisions, respectively. Other authors also observed that not all incomplete excisions recurred ${ }^{14,34}$. This probably occurs due to diathermic fulguration effect in the remained borders, so incomplete lesions can have earlier surveillance instead of rushed reoperation. There was no significant difference in recurrence rate for full thickness wall excision or mucosectomy in this series.

In a report of 116 resected adenomas, Palma, et al. ${ }^{30}$ observed $3.7 \%$ recurrence rate, all successfully managed by a second TEM. Similarly, Platell, et al. ${ }^{34}$ had a $2.4 \%$ recurrence rate in 62 adenomas, all re-excised by TEM.

From the above data it can conclude that TEM is safe and effective in rectal adenomas, allowing a better $\mathrm{RO}$ resection when compared to conventional transanal approach $^{27}$.

\section{Malignant lesions}

Large polyps can be hard to differentiate from rectal 
adenocarcinomas even after several biopsies. When facing this uncertainty, the authors perform a EURS and TEM is proposed to our patients as a diagnostic tool, allowing adequate pathological examination of the specimen.

When a malignant lesion is present or suspected, a full-thickness resection should be performed.

Low anterior or abdominoperineal resections are the definitive procedures in the radical treatment of malignant rectal lesions. Total excision of the mesorectum with or without preoperative combined modality therapy (CMT) has allowed better outcomes regarding recurrence and survival. However, patients have to experience long operative time and are exposed to postoperative complications such as bleeding, suture dehiscence, temporary or definitive colostomy, sexual or urinary dysfunctions, pneumonia and thromboembolic events. In this context, TEM appeared as an attractive alternative, however precise preoperative staging is imperative since the procedure does not remove all perirectal lymph nodes (the risk of its involvement is $0 \%-12 \%$ for T1 cancers, $12 \%-28 \%$ for T2 cancers, $36 \%$ $79 \%$ for $\mathrm{T3}$ cancers $\mathrm{s}^{25,32,35}$ ). Therefore, local recurrence is a major concern and careful patient selection is mandatory to optimize results.

\section{Early rectal cancers}

For the past decades TEM has been usually indicated for patients with low risk $\mathrm{T} 1$ adenocarcinomas. It is considered a low risk T1 lesion, those with favorable prognostic factors such as small size (less than four centimeters), absence of invasion of the sm2 or sm3 levels of the submucosa, well differentiated histology, and absence of vascular, lymphatic or perineural invasion. When these criteria are respected survival and local recurrence rates achieved by TEM are similar to those of radical treatment but with limited morbidity and mortality ${ }^{17,41}$.

Borschitz, et al. ${ }^{2}$ studied the long term results of patients with pT1 lesions resected by TEM. Patients were grouped as low or high risk for recurrence accordingly to histopathologic findings. The low risk group (RO) included 89 patients and observed a recurrence rate of $6 \%$, with 10 years cancer-free survival of $89 \%$. The high-risk group ( $R 1, R x$, unfavorable histologic criteria) included 21 patients and presented a recurrence rate of $39 \%$. This study observed that R0 resection in cases with low-risk PT1 carcinomas by TEM can be oncologic adequate with similar results when compared to primary radical surgery for $\mathrm{PT} 1 \mathrm{~N} 0 \mathrm{M} 0$ rectal lesions.

Heintz, et al. ${ }^{17}$ compared the results of TEM and radical surgery in 103 patients with $\mathrm{T} 1$ rectal carcinomas. TEM had significantly lower morbidity and mortality rates (3.4\% versus $18 \%$ and $0 \%$ versus $3.8 \%$, respectively). Regarding five years survival rate, no difference was observed between the procedures in those patients with low-risk T1 lesions. In patients with high-risk T1 carcinomas, lymph node metastases were identified in
$36 \%$ of those patients undergoing radical resection and recurrence was higher in the TEM group (33\% versus $0 \%)$.

Other studies have also demonstrated good results with low recurrence and high survival for selected pT1N0 rectal adenocarcinomas treated by TEM alone 2,4,8,13,20,21,36.

In the advent that pathological examination reveals a pT1 lesion with unfavorable features or a more advanced lesion the authors recommend complementary treatment with radical surgery and/or CMT.

\section{Locally advanced rectal cancers}

The treatment of T2 and T3 rectal lesions by TEM alone has proved to be inadequate with high recurrence rates $^{42}$. This is expected, since the risk of lymph node involvement for $\mathrm{T} 2$ and $\mathrm{T} 3$ rectal adenocarcinomas is high (12\%-28\% and 36\%-79\%, respectively $22,32,35)$.

Concerning T2 lesions, Lee, et al. ${ }^{21}$ compared patients with T1NOMO and T2NOMO rectal adenocarcinomas treated by TEM alone (74 patients) or by radical surgery (100 patients). No difference was observed concerning recurrence and five years survival in the pT1 group. In the pT2 group although no statistical difference was noted at five years survival rate, the TEM group carried an increased risk of local recurrence. They recommend careful selection of patients for TEM, counseling that when the muscular layer is invaded additional treatment should be performed. These findings are in accordance with other author's opinion that local excision alone for T2 rectal cancer is inadequate with a high risk for recurrence ${ }^{1,13,15,37,38,43}$. Borschitz, et al. $^{3}$ demonstrated a local recurrence rate of $29 \%$ to $50 \%$ for low-risk and high-risk T2 adenocarcinomas, respectively. Another recent study observed in median follow-up of three years that 12 patients with $\mathrm{T} 2$ rectal adenocarcinomas that undergone radiotherapy after TEM remained disease free, while a $50 \%$ recurrence rate was observed in four patients who refused adjuvant treatment ${ }^{10}$.

An adequate alternative for T2NO lesions with no distant metastases appears to be neoadjuvant or adjuvant therapy associated with $\mathrm{TEM}^{43}$. A prospective study with a median follow-up of 84 months included 70 patients with T2N0 adenocarcinoma at time of admission. Patients received preoperative CMT and were randomized in two groups (35 patients in each arm): one group underwent TEM and the other laparoscopic resection with total mesorectal excision. They observed similar results in terms of local recurrence, distant metastases and survival ${ }^{24}$. Perhaps if a larger number of patients had been enrolled, the recurrence rate $(5.7 \%$ for TEM versus $2.8 \%$ for laparoscopic resection) might have been statistically significant.

Lezoche, et al. ${ }^{23}$ studied patients with small (less than $3 \mathrm{~cm}$ in diameter) T2-3 NO distal rectal cancer undergoing high-dose radiotherapy before TEM. A total of 103 patients were enrolled (54 UT2N0 and 46 UT3N0). The definitive histological examination revealed nine $\mathrm{pT} 1$, 54 pT2 and 19 pT3 adenocarcinomas. Complete response 
or microscopic residual tumor was found in three and 15 patients, respectively. Minor complications occurred in 11 patients and major complications in two. At a median follow-up of 55 months, local failure rate was $5 \%$ and metastatic disease was found in two patients. Cancerspecific survival rate at a 90 months follow-up was $89 \%$ and overall survival rate $72 \%$. Salvage abdominoperineal resection was performed in three patients, two of whom were disease free at 15 and 19 months39.

\section{therapy}

Assessment of tumor response to combined modality

Proposing TEM after CMT for locally advanced rectal cancer requires confirming downstaging was achieved, which is difficult despite the use of all diagnostic tools (proctologic examination, EURS, CT, MRI, PET-CT, biopsies, serum carcinoembryogenic antigen levels). In this context TEM can be performed as a diagnostic tool that allows histologic examination and has therapeutic properties as well. Certifying complete clinical response can be difficult Based on this, TEM can have a major role as a diagnostic procedure in the selected group of patients who present complete clinical response and in those in which recurrence or persistence of tumor cannot be ruled out and biopsies only reveal actinic alterations. TEM allows pathologic evaluation of the rectal area involved with low morbidity. Currently, TEM can be an option for patients with complete clinical response and negative biopsies (TNM stage assessed eight weeks after the end of CMT). Outside these strict criteria the authors believe that only patients enrolled in protocol studies should underwent TEM, since radical resection remains the therapy of choice. Randomized controlled trials with a large number of cases and long follow-up comparing TEM with radical resection in patients with incomplete response are needed.

\section{Palliation}

Another possible indication for TEM is local palliation in selected patients with advanced disease, and patients that refuse or have a prohibitive risk for radical surgery (associated with radiotherapy and/or chemoterapy whenever possible). Those patients benefit from the limited morbidity and mortality and absence of surgical incision, short length of stay and fast recovery.

\section{Carcinoid tumor}

Rectal carcinoid tumors present relatively often at an early stage without distant metastases because they are incidentally found at endoscopy or with rectal bleeding. From a histopathological point of view it is important to differentiate between low grade carcinoid tumors and high grade neuroendocrine carcinomas, as the latter have a worse prognosis. Carcinoid tumors do not respond to chemotherapy and surgery is the therapy of choice. Criteria for local resection of rectal carcinoid tumors have been formulated. Unlike rectal carcinomas, the diameter of the tumor and the depth of invasion are the only relevant parameters for treating rectal carcinoid tumors. With a diameter $<1 \mathrm{~cm}$ and free margins, 5-year survival is reported at $100 \%$ after local excision. Invasion of the rectal wall is not observed in these tumors. In tumors with a diameter of 1 to $2 \mathrm{~cm}$, free margins, and no invasion, 5 -year survival is also $100 \%$. In cases of invasion, 5-year survival drops to $73 \%$. For lesions with more than $2 \mathrm{~cm}$ diameter, total mesorrectal excision is advised $^{19,29}$. No recurrences has been observed in the literature for carcinoid tumors of the rectum and even the distal part of the sigmoid treated by TEM, if the diameter is $<1 \mathrm{~cm}$ without invasion of the rectal wall ${ }^{7,18,33}$.

\section{Complications}

TEM is usually a quick procedure with an average operating time around 67 minutes ${ }^{12,28,34}$. Complication rate is approximately around $10 \%$, being fever, urinary retention, rectal bleeding and pain the most common. Rare complications are: abdominal perforation, transitory fecal incontinence and suture dehiscence with pelvic abscess. Few deaths are reported in the literature and most are in fact due to metastatic disease in the late postoperative or due to advanced disease in cases where palliative TEM was performed $12,13,14,27,30$. Both malignant and benign lesions have similar complication rates ${ }^{14}$. Conversion rate is around $5 \%$ occurring mainly due to technical difficulties.

When compared to rectal resections, such as low anterior resection or abdominoperineal resection, TEM has a reduced morbidity and mortality, the hospital length of stay is shorter and re-operation rate lower. Also, TEM is quicker to perform, does not require an abdominal incision and significantly reduces postoperative pain.

Concerning the functional results of the procedure, there has been some questions about fecal continence, since a $40 \mathrm{~mm}$ diameter proctoscope is inserted in the anus for a few hours. Most studies showed that despite manometric alterations can be found in the postoperative period they return to normal with time and no detriment in fecal continence are notice at any moment ${ }^{6,40}$. In fact, quality of life and even continence are improved after tumor removal ${ }^{9}$.

\section{CONCLUSIONS}

TEM is associated with low morbidity and mortality is practically nil. TEM is the technique of choice in large rectal adenomas, low risk pT1, and selected small neuroendocrine tumors localized in the rectal ampulla. The frequency of recurrence is similar to that in abdominal surgery. The technique does not cause complications of urinary or sexual dysfunction and fecal incontinence is minimal. In more advances stages of rectal adenocarcinoma, the results of better patient selection and future studies on the possible application of neoadjuvant/adjuvant therapy associated with TEM are required. 
REFERENCES

1. Bleday R, Breen E, Jessup JM, Burgess A, Sentovich SM, Steele G Jr. Prospective evaluation of local excision for small rectal cancers. Dis Colon Rectum 1997;40:388-92.

2. Borschitz T, Heintz A, Junginger T. The influence of histopathologic criteria on the long-term prognosis of locally excised pT1 rectal carcinomas: results of local excision (transanal endoscopic microsurgery) and immediate reoperation. Dis Colon Rectum. 2006 Oct:49(10):1492-506; discussion 1500-5.

3. Borschitz $T$, Heintz A, Junginger T. Transanal endoscopic microsurgical excision of pT2 rectal cancer: results and possible indications. Dis Colon Rectum. 2007 Mar;50(3):292-301.

4. Buess G, Mentges B, Manncke K, Starlinger M, Becker HD. Technique and results of transanal endoscopic microsurgery in early rectal cancer. Am J Surg 1992;163:63-70.

5. Buess G. Review: transanal endoscopic microsurgery (TEM). J R Coll Surg Edinb. 1993 Aug;38(4):239-45.

6. Cataldo PA, O'Brien S, Osler T. Transanal endoscopic microsurgery: a prospective evaluation of functional results. Dis Colon Rectum. 2005 Jul;48(7):1366-71.

7. de Graaf EJ, Doornebosch PG, Stassen LP, Debets JM, Tetteroo GW, Hop WC. Transanal endoscopic microsurgery for rectal cancer. Eur J Canc 2002;38:904-905.

8. Demartines N, von Flue MO, Harder FH. Transanal endoscopic microsurgical excision of rectal tumors: indications and results. World J Surg 2001;25:870-5.

9. Doornebosch PG, Gosselink MP, Neijenhuis PA, Schouten WR, Tollenaar RA, de Graaf EJ. Impact of transanal endoscopic microsurgery on functional outcome and quality of life. Int J Colorectal Dis. 2008 Jul;23(7):709-13.

10. Duek SD, Issa N, Hershko DD, Krausz MM. Outcome of transanal endoscopic microsurgery and adjuvant radiotherapy in patients with $\mathrm{t} 2$ rectal cancer. Dis Colon Rectum. 2008 Apr;51(4):379-84.

11. Endreseth $B H$, Wibe $A$, Svinsås $M$, Mårvik $R$, Myrvold $H E$. Postoperative morbidity and recurrence after local excision of rectal adenomas and rectal cancer by transanal endoscopic microsurgery. Colorectal Dis. 2005 Mar;7(2):133-7.

12. Farmer KC, Wale R, Winnett J, Cunningham I, Grossberg P, Polglase A. Transanal endoscopic microsurgery: the first 50 cases. ANZ J Surg. 2002 Dec;72(12):854-6.

13. Floyd ND, Saclarides TJ. Transanal endoscopic microsurgical resection of pT1 rectal tumors. Dis Colon Rectum. 2006 Feb;49(2):164-8.

14. Ganai S, Kanumuri P, Rao RS, Alexander AI. Local recurrence after transanal endoscopic microsurgery for rectal polyps and early cancers. Ann Surg Oncol. 2006 Apr;13(4):547-56.

15. Garcia-Aguilar J, Mellgren A, Sirivongs P, Buie D, Madoff RD, Rothenberger DA Local excision of rectal cancer without adjuvant therapy: a word of caution. Ann Surg 2000 231:345-51.

16. Guerrieri $M$, Baldarelli $M$, Morino $M$, Trompetto $M$, Da Rold $A$, Selmi I, Allaix ME, Lezoche G, Lezoche E. Transanal endoscopic microsurgery in rectal adenomas: experience of six Italian centres. Dig Liver Dis. 2006 Mar;38(3):202-7

17. Heintz $A$, Mörschel $M$, Junginger T. Comparison of results after transanal endoscopic microsurgery and radical resection for $\mathrm{T} 1$ carcinoma of the rectum. Surg Endosc. 1998 Sep;12(9):1145-8.

18. Kinoshita T, Kanehira E, Omura K, Tomori T, Yamada H. Transanal endoscopic microsurgery in the treatment of rectal carcinoid tumor. Surg Endosc. 2007 Jun;21(6):970-4.

19. Koura AN, Giacco GG, Curley SA, Skibber JM, Feig BW, Ellis LM. Carcinoid tumours of the rectum: effect of size, histopathology, and surgical treatment on metastasis free survival. Cancer 1997;79: 1294-1297.

20. Langer C, Markus P, Liersch T, Fuzesi L, Becker H. UltraCision or high-frequency knife in transanal endoscopic microsurgery (TEM)? Advantages of a new procedure. Surg Endosc 2001;15:513-7.

21. Lee W, Lee $D$, Choi S, Chun H. Transanal endoscopic microsurgery and radical surgery for T1 and T2 rectal cancer. Surg Endosc 2003;17:1283-7.

22. Lev-Chelouche D, Margel D, Goldman G, Rabau MJ. Transanal endoscopic microsurgery: experience with 75 rectal neoplasms. Dis Colon Rectum 2000;43:662-7.
23. Lezoche $E$, Guerrieri M, Paganini AM, Baldarelli M, De Sanctis A, Lezoche $\mathrm{G}$. Long-term results in patients with T2-3 N0 distal rectal cancer undergoing radiotherapy before transanal endoscopic microsurgery.Br J Surg. 2005 Dec;92(12):1546-52.

24. Lezoche G, Baldarelli $M$, Guerrieri $M$, Paganini AM, De Sanctis $A$, Bartolacci $S$, Lezoche E.. A prospective randomized study with a 5-year minimum follow-up evaluation of transanal endoscopic microsurgery versus laparoscopic total mesorectal excision after neoadjuvant therapy. Surg Endosc. 2008 Feb;22(2):352-8.

25. Madbouly KM, Remzi FH, Erkek BA, Senagore AJ, Baeslach CM, Khandwala F, Fazio VW, Lavery IC. Recurrence after transanal excision of T1 rectal cancer: should we be concerned? Dis Colon Rectum 2005; 48: 711-19; discussion 719-21.

26. McCloud JM, Waymont N, Pahwa N, Varghese P, Richards C, Jameson JS, Scott AN. Factors predicting early recurrence after transanal endoscopic microsurgery excision for rectal adenoma. Colorectal Dis. 2006 Sep;8(7):581-5.

27. Middleton PF, Sutherland LM, Maddern GJ. Transanal endoscopic microsurgery: a systematic review. Dis Colon Rectum. 2005 Feb;48(2):270-84.

28. Mihai R, Borley N. Transanal endoscopic microsurgery-impact on the practice of a colorectal surgeon in a district general hospital. Ann R Coll Surg Engl. 2005 Nov;87(6):432-6.

29. Naunheim KS, Zeitels J, Kaplan EL, Sugimoto J, Shen KL, Lee CH, Straus FH 2nd. Rectal carcinoid tumors: treatment and prognosis. Surgery 1983;94:670-675.

30. Palma P, Freudenberg S, Samel S, Post S. Transanal Endoscopic Microsurgery: Indications and Results After 161 Cases. Colorectal Dis. 2004; 6 (1):56.

31. Papagrigoriadis S. Transanal endoscopic micro-surgery (TEMS) for the management of large or sessile rectal adenomas: a review of the technique and indications. Int Semin Surg Oncol. 2006 May 4;3:13.

32. Paty PB, Nash GM, Baron P, Zakowski M, Minsky BD, Blumberg D, Nathanson DR, Guillem JG, Enker WE, Cohen AM, Wong WD. Longterm results of local excision for rectal cancer. Ann Surg 2002; 236: 522-9; discussion 529-30.

33. Peerbooms JC, Simons JL, Tetteroo GW, De Graaf EJ. Curative resection of rectal carcinoid tumors with transanal endoscopic microsurgery. J Laparoendosc Adv Surg Tech A. 2006 Oct;16(5):435-8

34. Platell C, Denholm E, Makin G. Efficacy of transanal endoscopic microsurgery in the management of rectal polyps. J Gastroenterol Hepatol. 2004 Jul;19(7):767-72.

35. Sengupta S, Tjandra JJ. Local excision of rectal cancer: what is the evidence? Dis Colon Rectum 2001; 44: 1345-61.

36. Smith LE, Ko ST, Saclarides T, Caushaj P, Orkin BA, Khanduja KS. Transanal endoscopic microsurgery. Initial registry results. Dis Colon Rectum 1996;39:79-84.

37. Stipa F, Lucandri G, Ferri M, Casula G, Ziparo V. Local excision of rectal cancer with transanal endoscopic microsurgery (TEM). Anticancer Res 2004; 24:1167-72.

38. Taylor RH, Hay JH, Larsson SN. Transanal local excision of selected low rectal cancers. Am J Surg 1998;175:360-3.

39. Tjandra T. Long-term results in patients with T2-3 NO distal rectal cancer undergoing radiotherapy before transanal endoscopic microsurgery. Tech Coloproctol. 2006 Jul;10(2):158; discussion 158-9.

40. Wang HS, Lin JK, Yang SH, Jiang JK, Chen WS, Lin TC. Prospective study of the functional results of transanal endoscopic microsurgery. Hepatogastroenterology. 2003 Sep-Oct;50(53):1376-80.

41. Winde G, Nottberg H, Keller R, Schmid KW, Bünte H. Surgical cure for early rectal carcinomas (T1). Transanal endoscopic microsurgery vs. anterior resection. Dis Colon Rectum. 1996 Sep;39(9):969-76.

42. Zacharakis E, Freilich S, Rekhraj S, Athanasiou T, Paraskeva P, Ziprin P, Darzi A. Transanal endoscopic microsurgery for rectal tumors: the St. Mary's experience. Am J Surg. 2007 Nov;194(5):694-8.

43. Zieren J, Paul M, Menenakos C. Transanal endoscopic microsurgery (TEM) vs. radical surgery (RS) in the treatment of rectal cancer: indications, limitations, prospectives. A review. Acta Gastroenterol Belg. 2007 Oct-Dec;70(4):374-80. 